\title{
A infecção por coronavírus e a cardiomiopatia de Takotsubo na era da pandemia do SARS-COV 2
}

\author{
Coronavirus infection and Takotsubo cardiomyopathy in the SARS-COV 2 pandemic age \\ Infección por coronavirus y cardiomiopatía de Takotsubo en la pandemia de SARS-COV 2
}

Rackel Santana Marques de Souza ${ }^{1 *}$, Gledson Lima Alves Junior ${ }^{1}$, Victoria Haydée Deusdedith Neves ${ }^{1}$, Vitor Moura Pereira ${ }^{1}$, Ursula Maria Moreira Costa Burgos ${ }^{2}$.

\begin{abstract}
RESUMO
Objetivo: Relacionar a ocorrência de cardiomiopatia de Takotsubo e complicações associadas em pacientes infectados pela COVID-19 no contexto pandêmico atual. Métodos: Trata-se é uma revisão da literatura atual e foram incluídos 22 artigos da plataforma PUBMED, utilizando os seguintes descritores: "Takotsubo cardiomyopathy", "Coronavirus infections" e "Heart diseases". Resultados: Os mais recentes estudos evidenciam um aumento do número de casos novos da cardiomiopatia de Takotsubo desde que a pandemia do COVID-19 alastrou-se pelo mundo, quando foi observado o aumento de $5.95 \%$ de casos da doença em relação a períodos anteriores. A predileção cardíaca do vírus se mostra parcialmente elucidada pela associação entre a lesão endotelial e a invasão viral, sendo assim, capaz de deflagrar patologias cardíacas. Ademais, os efeitos psicológicos causados pelo isolamento social, crise sanitária e financeira também exerceram forte influência sobre o desencadeamento da cardiomiopatia. Considerações finais: Deste modo, a doença causada pelo SARS-CoV 2 associa-se à complicações como a cardiomiopatia de Takotsubo que, por sua vez, implica em aumento da taxa de mortalidade. Por conseguinte, evidencia-se a necessidade de diagnosticá-la precocemente, em especial, em pacientes de alto risco, a fim de melhorar os desfechos clínicos e reduzir o período de internação.
\end{abstract}

Palavras-chave: Cardiomiopatia de Takotsubo, Infecção por coronavirus, Doenças do coração.

\begin{abstract}
Objective: To relate the occurrence of Takotsubo's cardiomyopathy and associated complications in patients infected with COVID-19 in the current pandemic context. Methods: This is a review of the current literature and 22 articles from the PUBMED platform were included, using the following descriptors: "Takotsubo cardiomyopathy", "coronavirus infections" and "heart diseases". Results: The most recent studies show an increase in the number of new cases of Takotsubo cardiomyopathy since the COVID-19 pandemic spread around the world, when a $5.95 \%$ increase in cases of this disease was observed in relation to previous periods. The cardiac predilection of the virus is partially elucidated by the association between endothelial injury and viral invasion, thus being able to trigger cardiac pathologies. In addition, the psychological effects caused by social isolation, health and financial crisis also had a strong influence on the triggering of cardiomyopathy. Final considerations: Thus, the disease caused by SARS-CoV 2 is associated with complications, which can lead to Takotsubo's cardiomyopathy, and, in turn, to an increase in the mortality rate. Therefore, it is necessary to diagnose it early, especially in high-risk patients, in order to improve clinical outcomes and reduce the length of hospital stay.
\end{abstract}

Key words: Takotsubo cardiomyopathy, Coronavirus infections, Heart diseases.

\section{RESUMEN}

Objetivo: Relacionar la ocurrencia de la miocardiopatía de Takotsubo y las complicaciones asociadas en pacientes infectados por COVID-19 en el contexto pandémico actual. Métodos: Es una revisión de la literatura actual y se incluyeron 22 artículos de la plataforma PUBMED, utilizando los siguientes descriptores:

1 Universidade Tiradentes (UNIT), Aracaju - SE. *E-mail: kel1001@hotmail.com

2 Universidade Federal de Sergipe (UFS), São Cristóvão - SE. 
"Takotsubo cardiomyopathy", "Coronavirus infections" y "Heart diseases". Resultados: Los estudios más recientes muestran un aumento en el número de nuevos casos de miocardiopatía de Takotsubo desde que la pandemia COVID-19 se extendió por todo el mundo, cuando se observó un aumento del 5,95\% en los casos de la enfermedad en relación a períodos anteriores. La predilección cardíaca del virus se dilucida parcialmente por la asociación entre lesión endotelial e invasión viral, pudiendo desencadenar patologías cardíacas. Además, los efectos psicológicos causados por el aislamiento social, la salud y la crisis financiera también tuvieron una fuerte influencia en el desencadenamiento de la miocardiopatía. Consideraciones finales: Así, la enfermedad causada por SARS-CoV 2 se asocia a complicaciones como la miocardiopatía de Takotsubo, que a su vez implica un aumento de la tasa de mortalidad. Por tanto, es necesario diagnosticarlo de forma precoz, especialmente en pacientes de alto riesgo, para mejorar los resultados clínicos y reducir la duración de la estancia hospitalaria.

Palabras clave: Miocardiopatía de Takotsubo, Infecciones por coronavirus, Enfermedades cardíacas.

\section{INTRODUÇÃO}

Desde que os primeiros casos surgiram em Wuhan, China, a doença do Coronavírus 19 (COVID-19), causada pelo Severe Acute Respiratory Syndrome Coronavirus 2 (SARS-CoV 2), se alastrou pelo mundo, resultando em uma pandemia que atingiu milhares de pessoas. Em meados do mês de junho de 2020, havia em torno de 8,5 milhões de indivíduos infectados, enquanto que o número absoluto de mortes se encontrava em torno de 450 mil distribuídos entre os países de todo o mundo (ZHOU R, 2020; JABRI A, et al., 2020).

Nesse sentido, é importante mencionar que a infecção por SARS-COV 2 apresenta amplo espectro de manifestações clínicas, desde quadros assintomáticos a apresentações clínicas graves, com manifestação de falência respiratória, choque e nos casos mais críticos, morte. Além da comprovada agressão pulmonar, ela também é capaz de gerar lesão nos sistemas cardiovascular, hematológico, gastrointestinal, urinário, reprodutor e neurológico (GOMEZ JMD, et al., 2020; FINSTERER J e STÖLLBERGER C, 2020).

Dessa forma, é possível verificar que o vírus SARS-COV 2 tem caráter progressivo em termo de acometimento clínico, apresentando, de modo geral, uma primeira fase com sintomas constitucionais, seguida de uma fase marcada pela ação direta do vírus no trato respiratório. Esta, por sua vez, pode evoluir para quadros de insuficiência respiratória e síndrome do desconforto respiratório agudo grave. Por fim, uma terceira e última fase, mediada pela resposta hiperinflamatória do vírus e causadora de efeitos deletérios em vários sistemas, incluindo o cardiovascular (LANG JP, et al., 2020).

Dentre as manifestações cardiovasculares, podem ser identificados casos de arritmias cardíacas, distúrbios de condução, miocardite, cardiomiopatia por estresse, lesões miocárdicas e isquemia/ infarto miocárdico. Além dos efeitos cardíacos diretos, o estresse psicológico, decorrente do isolamento social e turbulência de notícias deste período, provavelmente se associam a uma condição conhecida como Cardiomiopatia de Takotsubo (CT) (KIR D et al., 2021).

A cardiomiopatia de Takotsubo, descrita pela primeira vez no Japão em 1990, é uma condição clínica caracterizada pela disfunção aguda e transitória do ventrículo esquerdo e, em geral, encontra-se relacionada a eventos estressores agudos, sejam eles emocionais ou físicos. No entanto, é válido mencionar que os eventos estressores agudos não são exclusivamente aqueles estresses emocionais negativos: há documentação na literatura de casos de CT associados a estressores emocionais positivos, sendo nessa situação, denominada de síndrome do coração feliz (HEGDE S, et al., 2020; OKURA H, 2020).

Foi percebido aumento do número de casos de CT no ano de 2020, quando comparado a 2019, principalmente, durante o período de lockdown (isolamento social como medida de contenção de agravamento da pandemia), ratificando a possível associação com a COVID-19 (BARBIERI L, et al., 2021).

Destarte, esta revisão bibliográfica foi fomentada pela observação do aumento do número de casos da cardiomiopatia induzida por estresse no período da pandemia do COVID-19, em virtude da elevação do número de internações e do tempo de permanência hospitalar relacionados à ocorrência da doença em questão, além da sua ampla gama de diagnósticos diferenciais. Objetivou-se, por conseguinte, a maior 
compreensão das interferências do vírus e dos efeitos da pandemia no sistema cardiovascular, resultando na Cardiomiopatia de Takotsubo.

\section{MÉTODOS}

O presente artigo é uma revisão integrativa da literatura atual, com análise e síntese dos resultados observados. O questionamento norteador da presente revisão foi "Qual a relação entre a ocorrência de cardiomiopatia de Takotsubo e epidemia pelo SARS-CoV-2?".

Foi realizada uma pesquisa através da base de dados Medical Literature Analysis and Retrieval System Online (MEDLINE), mediante o mecanismo de busca Public/ Publisher MEDLINE (PubMed). Os descritores de interesse, encontrados por meio da ferramenta Medical Subject Headings (MeSH), foram Takotsubo cardiomyopathy, coronavirus infections e heart diseases, os quais foram selecionados com base em publicações prévias sobre o objeto de estudo e combinados na seguinte estratégia de busca "((Takotsubo Cardiomyopathy) AND (Coronavirus Infections)) AND (Heart Diseases)".

Os critérios de inclusão utilizados na presente pesquisa foram: artigos na base de dados selecionada em português e/ou inglês e publicados nos últimos cinco anos. Os critérios de exclusão foram os artigos publicados em línguas diferentes das utilizadas pelo critério de inclusão, os com textos incompletos e os que ultrapassavam a data-limite de cinco anos (Figura 1).

Figura 1 - Fluxograma de critérios de inclusão e exclusão da pesquisa.

Artigos encontrados na base de dados PubMed $(n=50)$

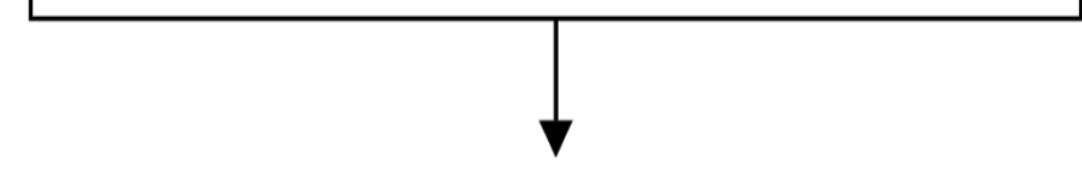

Estudos publicados em idioma português e/ou inglês ( $n=48)$

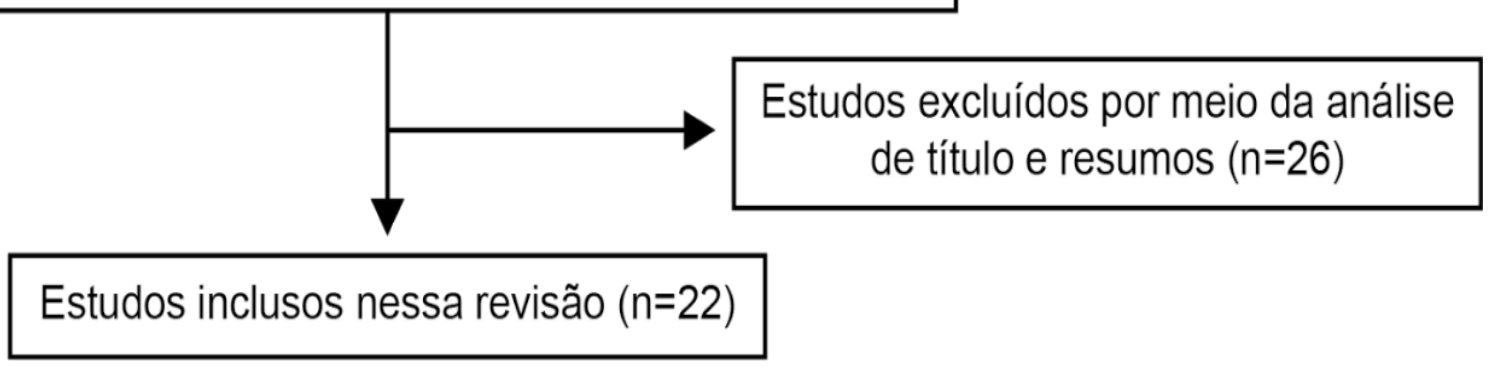

Fonte: Souza R, et al., 2021.

A busca foi estabelecida através de acesso online dos artigos relevantes durante o mês de abril de 2021. Posteriormente, foi realizada análise criteriosa do material selecionado a fim de reunir as informações mais relevantes concernentes ao tema proposto.

\section{RESULTADOS E DISCUSSÃO}

Nesta revisão de literatura foram incluídos 22 artigos, dentre os 50 encontrados no momento da busca. Foram descartados aqueles resultados que não abrangiam os critérios desejados. No Quadro 1 estão dispostos os artigos selecionados e utilizados na construção deste texto, juntamente aos seus objetivos e resultados. 
Quadro 1 - Objetivos e principais resultados encontrados nos artigos selecionados.

\begin{tabular}{|c|c|c|}
\hline Autor & Objetivo de estudo & Resultados \\
\hline $\begin{array}{l}\text { Barbieri L, et al. } \\
(2021)\end{array}$ & $\begin{array}{l}\text { Descrever uma série de casos de CT, com a descrição } \\
\text { médica e psicológica dos pacientes internados no hospital } \\
\text { durante o pico da pandemia na Itália. }\end{array}$ & $\begin{array}{l}\text { De fevereiro a maio de } 2020,11 \text { pacientes foram diagnosticados com CT no hospital em que foi } \\
\text { realizada a pesquisa. Durante o mesmo período, em } 2019 \text {, apenas } 3 \text { casos foram relatados. } \\
\text { Indivíduos que foram acometidos por experiências de estresse psicológico pré-pandêmico } \\
\text { podem sofrer sobrecarga psicológica adicional, abrindo as portas para a CT por uma série de } \\
\text { alterações fisiológicas, tornando o sujeito mais vulnerável ao início da CT. A avaliação } \\
\text { psicológica de } 6 \text { dos } 11 \text { pacientes estudados demonstrou que estes viveram um período de } \\
\text { grande estresse emocional no último ano. }\end{array}$ \\
\hline $\begin{array}{l}\text { Everaert BR, et al. } \\
(2020)\end{array}$ & $\begin{array}{l}\text { Problemas cardiológicos precipitados pela pandemia do } \\
\text { COVID-19. }\end{array}$ & $\begin{array}{l}\text { A pandemia causada pelo COVID-19 traz implicações importantes para o cuidado } \\
\text { cardiovascular de nossos pacientes, seja por colocá-los em risco aumentado ou por afetar a } \\
\text { forma como tratamos ou cuidamos de nossos pacientes. }\end{array}$ \\
\hline $\begin{array}{l}\text { Faqihi } F \text {, et al. } \\
(2020)\end{array}$ & $\begin{array}{l}\text { Analisar, através de um relato de caso, a ocorrência de } \\
\text { Cardiomiopatia Takotsubo (CT) em pacientes com COVID- } \\
\text { 19. }\end{array}$ & $\begin{array}{l}\text { A cardiomiopatia de estresse pode complicar o curso de COVID-19 fulminante com liberação } \\
\text { imediata de citocinas associadas. Se a terapia inotrópica falha, a terapia de transfusão de } \\
\text { plasma sem anticorpos protetores pode ajudar a resgatar o paciente em estado crítico. }\end{array}$ \\
\hline 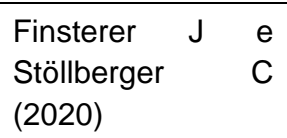 & $\begin{array}{l}\text { Reportar } 38 \text { casos de miocardiopatia de Takotsubo } \\
\text { engatilhados por COVID-19. }\end{array}$ & $\begin{array}{l}\text { Conclui-se que houve um aumento de casos de Takotsubo em relação aos períodos anteriores } \\
\text { ao COVID-19. }\end{array}$ \\
\hline $\begin{array}{l}\text { Gomez JMD, et al. } \\
(2020)\end{array}$ & $\begin{array}{l}\text { Relato de caso, em que consta paciente feminino, } 57 \text { anos, } \\
\text { que desenvolveu CT e choque misto, cardiogênico e séptico, } \\
\text { na manifestação patológica da COVID-19. }\end{array}$ & $\begin{array}{l}\text { Destaca-se, dessa forma, neste estudo, a importância da abordagem multidisciplinar para a } \\
\text { tomada de decisões clínicas e alocação de recursos no diagnóstico e tratamento de doenças } \\
\text { críticas no cenário da pandemia COVID-19 em curso. }\end{array}$ \\
\hline $\begin{array}{l}\text { Hegde S, et al. } \\
(2020)\end{array}$ & $\begin{array}{l}\text { Aumentar a compreensão da CT secundária associada à } \\
\text { pneumonia COVID-19. }\end{array}$ & $\begin{array}{l}\text { O papel exato do SARS-CoV-2 no desenvolvimento de CT ainda não foi determinado. Os } \\
\text { possíveis mecanismos podem ser uma interação da proteína spike viral com os receptores ACE2 } \\
\text { no coração, estado pró-coagulante criado pelo vírus, dano miocárdico direto, lesão endotelial e } \\
\text { disfunção microvascular. A mortalidade de pacientes com CT secundária com COVID-19 é alta, } \\
\text { e o diagnóstico precoce e o manejo adequado são essenciais para melhorar os resultados. }\end{array}$ \\
\hline $\begin{array}{l}\text { Jabri } \\
(2020)\end{array}$ & $\begin{array}{l}\text { Determinar a incidência e resultados do estresse } \\
\text { cardiomiopático durante a pandemia COVID-19 em relação } \\
\text { ao período pré-pandemia. }\end{array}$ & $\begin{array}{l}\text { Este estudo demonstrou que há um importante aumento do número de incidência do estresse } \\
\text { cardiomiopático durante a pandemia COVID-19 em relação ao período pré-pandemia. }\end{array}$ \\
\hline Kir D, et al. (2021) & $\begin{array}{l}\text { Apresentar dois casos de pacientes com diagnóstico de } \\
\text { cardiomiopatia de estresse causada por trauma psicológico } \\
\text { devido à pandemia em curso. }\end{array}$ & $\begin{array}{l}\text { Necessidade de fornecer cuidados psiquiátricos e aconselhamento psicológico por meio da } \\
\text { telessaúde, para ajudar a diminuir a incidência de cardiomiopatia de Takotsubo durante a } \\
\text { pandemia. }\end{array}$ \\
\hline
\end{tabular}




\begin{tabular}{|c|c|c|}
\hline Autor & Objetivo de estudo & Resultados \\
\hline $\begin{array}{l}\text { Koutroumpakis E, } \\
\text { et al. }(2020)\end{array}$ & $\begin{array}{l}\text { Relato de caso em que objetiva descrever o } \\
\text { desenvolvimento de cardiomiopatia de estresse em um } \\
\text { paciente estava extremamente estressado por assistir o } \\
\text { cobertura de notícia da pandemia COVID-19. }\end{array}$ & $\begin{array}{l}\text { As causas mais comumente relatadas de estresse cardiovascular miopatia incluem perda de } \\
\text { entes queridos, desastres naturais, perda financeira significativa, agressão e violência, com } \\
\text { todos resultando em uma sensação de desgraça, perigo ou significante desespero. Isso é } \\
\text { consistente com nosso paciente, que se apresenta depois de se sentir desesperado e em perigo } \\
\text { de assistir às notícias sobre a pandemia COVID-19. }\end{array}$ \\
\hline $\begin{array}{l}\text { Lang JP, et al. } \\
(2020)\end{array}$ & $\begin{array}{l}\text { Sintetizar as evidências clínicas publicadas, até o momento, } \\
\text { sobre as complicações cardiovasculares do COVID-19, as } \\
\text { perspectivas emergentes sobre sua fisiopatologia e as } \\
\text { melhores práticas em evolução para a gestão clínica. }\end{array}$ & O autor não chegou a nenhuma conclusão definitiva. \\
\hline Madias JE (2021) & $\begin{array}{l}\text { Analisar a existência de subdiagnósticos de CT em pacientes } \\
\text { com COVID-19. }\end{array}$ & $\begin{array}{l}\text { Este resultado sugere a realização do ultrassonografia à beira leito para identificação de CT, } \\
\text { assim como outras afecções cardíacas, com o intuito de minimizar a exposição de diversos } \\
\text { profissionais que acontece durante a realização de outras modalidades de exames de imagem. }\end{array}$ \\
\hline $\begin{array}{l}\text { Moady G e Atar S } \\
(2021)\end{array}$ & $\begin{array}{l}\text { Relato de caso em que descreveu } 2 \text { casos de CT } \\
\text { desencadeados durante o período da pandemia da COVID- } \\
19 .\end{array}$ & $\begin{array}{l}\text { Miocardite deve ser um diagnóstico diferencial de CT, mas enquanto a primeira associa-se a } \\
\text { elevados níveis de troponina, a última relaciona-se a níveis de troponina moderados, além de } \\
\text { altas taxas de peptídeo natriurético e balonamento apical ao ecocardiograma. Múltiplos estudos } \\
\text { ainda se mostram controversos. É necessário um alto índice de suspeição para fazer o } \\
\text { diagnóstico desta condição clínica. }\end{array}$ \\
\hline Okura H (2020) & $\begin{array}{l}\text { Resumir uma atualização da CT em época de pandemia de } \\
\text { COVID-19. }\end{array}$ & $\begin{array}{l}\text { Fisiopatologia: há suspeita do papel das catecolaminas no desenvolvimento do CT, porém, os } \\
\text { mecanismos exatos ainda são incertos. Contudo, tanto o estresse emocional quanto o estresse } \\
\text { físico, por infecção em si, são considerados possíveis desencadeadores de CT típico, bem como } \\
\text { atípico em pacientes com COVID-19. } \\
\text { Diagnóstico: ressalta a importância do ecocardiograma, e aborda os critérios de Mayo e os } \\
\text { critérios de InterTAK. Além disso, ressalta que, em ambos os critérios a doença arterial crônica } \\
\text { não apresenta critério de exclusão da CT, podendo ser até um fator etiológico. } \\
\text { Tratamento: Não há estudo randomizado para avaliar o impacto prognóstico do tratamento. Foi } \\
\text { considerado betabloqueadores em alguns estudos, no entanto, sem resultados claros, já os } \\
\text { inibidores da enzima conversora de angiotensina e os antagonistas de angiotensina foram } \\
\text { associados a melhor sobrevida, sendo esse último associado a redução do risco de recorrência. }\end{array}$ \\
\hline $\begin{array}{l}\text { Peretto G, et al. } \\
(2020)\end{array}$ & $\begin{array}{l}\text { Melhorar a caracterização de envolvimento miocárdico } \\
\text { associado ao coronavírus. }\end{array}$ & $\begin{array}{l}\text { Mais dados de EMB/autópsia são necessários para estabelecer os mecanismos de lesão } \\
\text { miocárdica em COVID-19, incluindo seu papel potencial como uma nova causa de miocardite } \\
\text { viral. }\end{array}$ \\
\hline $\begin{array}{l}\text { Rivers J e Ihle JF } \\
(2020)\end{array}$ & $\begin{array}{l}\text { Relato de caso de cardiomiopatia Takotsubo provocada pelo } \\
\text { estresse durante isolamento social. }\end{array}$ & $\begin{array}{l}\text { O presente relato apontou que o isolamento social é prejudicial à saúde mental, associado com } \\
\text { aumento dos níveis de estresse e ansiedade, especialmente em pessoas mais velhas, que } \\
\text { podem ser menos capazes de usar a tecnologia para permanecer em contato com amigos e } \\
\text { família. Neste caso, o estresse foi o suficiente para desencadear cardiomiopatia Takotsubo. }\end{array}$ \\
\hline
\end{tabular}




\begin{tabular}{|c|c|c|}
\hline Autor & Objetivo de estudo & Resultados \\
\hline $\begin{array}{l}\text { Salah HM e Mehta } \\
\text { JL (2020) }\end{array}$ & $\begin{array}{l}\text { Analisar, a partir de uma revisão de } 10 \text { casos, a ocorrência } \\
\text { da CT em pacientes com COVID-19 }\end{array}$ & $\begin{array}{l}\text { O presente estudo não adquiriu conclusões definitivas. Dessa forma, tornam-se necessários } \\
\text { estudos que comparem os níveis de cortisol e outros fatores relacionados aos hormônios de } \\
\text { estresse entre pacientes com infecção por CT e COVID-19 e outros com COVID-19 sem CT. } \\
\text { Diante disso, tais feitos irão avançar nossa compreensão da fisiopatologia da CT e do papel dos } \\
\text { hormônios relacionados ao estresse nesta doença. }\end{array}$ \\
\hline $\begin{array}{l}\text { Shah RM, et al. } \\
(2020)\end{array}$ & $\begin{array}{l}\text { Entender a conexão entre síndrome de Takotsubo e o } \\
\text { coronavírus }\end{array}$ & $\begin{array}{l}\text { Parece haver uma associação entre cardiomiopatia induzida por estresse e COVID-19 tanto na } \\
\text { população geral que sofre com os efeitos psicossociais adversos da pandemia quanto em } \\
\text { pacientes com COVID-19. Para melhor quantificar o aumento geral nos casos de cardiopatia } \\
\text { induzida por estresse, estudos adicionais devem ser realizados com tamanhos de coortes } \\
\text { maiores. }\end{array}$ \\
\hline $\begin{array}{l}\text { Solano-López J, et } \\
\text { al. (2020) }\end{array}$ & $\begin{array}{l}\text { Apresentar um caso não usual de CT associado ao SARS- } \\
\text { CoV-2. }\end{array}$ & $\begin{array}{l}\text { Os autores afirmam, que dentro do conhecimentos deles, esse é o primeiro caso relatado de CT } \\
\text { invertido associado à infecção por SARS-CoV-2. }\end{array}$ \\
\hline $\begin{array}{l}\text { Szarpak L, et al. } \\
(2020)\end{array}$ & $\begin{array}{l}\text { Respaldar a hipótese de que a CT pode ser correlacionada } \\
\text { com a infecção do COVID-19. }\end{array}$ & $\begin{array}{l}\text { De acordo com os casos analisados, a CT deve ser considerada no diagnóstico diferencial em } \\
\text { todo o espectro de lesão miocárdica em pacientes infectados com SARS-CoV- } 2 \text {. }\end{array}$ \\
\hline $\begin{array}{l}\text { Taza } F \text {, et al. } \\
(2020)\end{array}$ & $\begin{array}{l}\text { Apresentar um caso de síndrome de Takotsubo em um } \\
\text { paciente com infecção por COVID-19. }\end{array}$ & $\begin{array}{l}\text { Resulta em uma hipótese de que a síndrome de liberação de citocinas desencadeada por } \\
\text { COVID-19 com um aumento subsequente de catecolaminas pode desempenhar um papel na } \\
\text { patogênese da síndrome de Takotsubo em pacientes com infecções por COVID-19. }\end{array}$ \\
\hline $\begin{array}{l}\text { Templin C, et al. } \\
(2021)\end{array}$ & $\begin{array}{l}\text { Analisar relatos de casos que correlacionam a presença CT } \\
\text { e a COVID-19. }\end{array}$ & $\begin{array}{l}\text { A CT e a COVID-19 provavelmente exercem efeitos sinérgicos no desenvolvimento de } \\
\text { problemas cardíacos. A tempestade de citocinas da COVID-19, associada à hiperativação } \\
\text { simpática da CT, resulta em disfunção microcirculatória, podendo esta causar insuficiência } \\
\text { cardíaca aguda descompensada. }\end{array}$ \\
\hline $\begin{array}{l}\text { Tsao CW, et al. } \\
(2020)\end{array}$ & $\begin{array}{l}\text { Discutir o caso de um paciente sem histórico de doença } \\
\text { cardiovascular que desenvolveu e se recuperou de } \\
\text { cardiomiopatia de estresse clínico no contexto de infecção } \\
\text { COVID-19 grave. }\end{array}$ & $\begin{array}{l}\text { A cardiomiopatia de estresse reversível pode ocorrer no contexto de infecção por COVID-19 } \\
\text { com elevados biomarcadores inflamatórios e cardíacos e um ECG anormal. A fisiopatologia da } \\
\text { miocardiopatia por estresse COVID-19 pode envolver mecanismos compartilhados entre a } \\
\text { cardiomiopatia por estresse não infecciosa e a miocardite viral. Estudos colaborativos e } \\
\text { longitudinais são necessários para avaliar o mecanismo subjacente e os resultados a longo } \\
\text { prazo da cardiomiopatia de estresse associada a COVID-19. }\end{array}$ \\
\hline Zhou R (2020) & $\begin{array}{l}\text { O SARS-CoV-2 causa miocardite viral em pacientes com } \\
\text { COVID- } 19 .\end{array}$ & $\begin{array}{l}\text { Não está claro se a lesão cardíaca observada em pacientes COVID-19 resulta diretamente da } \\
\text { infecção viral do miocárdio ou indiretamente das complicações do COVID-19. }\end{array}$ \\
\hline
\end{tabular}

Fonte: Souza R, et al., 2021. 
Pacientes com fatores de risco como Hipertensão Arterial Sistêmica (HAS), Diabetes Mellitus (DM) e portadores de doença cardiovascular prévia, quando afetados pela COVID-19, tendem a apresentar pior desfecho clínico e maior mortalidade. Em um estudo feito pelo Centro Chinês de Controle e Prevenção de Doenças, dos pacientes com COVID-19 que evoluíram para óbito, 40\% apresentavam hipertensão, 20\% diabetes e $20 \%$ já apresentavam alguma doença cardiovascular. É importante salientar ainda que essas comorbidades aparecem com mais frequência com o avançar da idade, o que corrobora com o fato de que pacientes mais velhos têm pior desfecho e maior morbimortalidade (LANG JP, et al., 2020).

Em pacientes hospitalizados com COVID-19, faz-se comum o encontro de alterações como elevação de biomarcadores cardíacos (ex.: troponina sérica), alteração dos parâmetros eletrocardiográficos e disfunção miocárdica. No estudo de Zhou R. et al (2020), dos 191 pacientes com infecção confirmada pelo SARS-COV2, $17 \%$ apresentavam lesão cardíaca e os níveis de troponina foram mais altos entre os não sobreviventes. Foi observado também que a prevalência de injúria miocárdica foi maior em pacientes mais velhos e multimórbidos, portadores de lesão renal crônica, doença pulmonar obstrutiva crônica (DPOC), doença cerebrovascular, DM e HAS (LANG JP, et al., 2020).

A predileção cardíaca do vírus é parcialmente elucidada pela associação entre a invasão viral e a lesão endotelial através da enzima conversora de angiotensina 2, cuja expressão é acentuada nos tecidos pulmonares e cardíacos. Isso, por sua vez, justificaria o fato de pacientes com hipertensão, logo com upregulation desses receptores, apresentarem maior possibilidade de contrair essa patologia (LANG JP, et al., 2020; TSAO CW, et al., 2020).

Diante disso, o desenvolvimento de lesão miocárdica no curso da infecção pelo SARS-CoV-2 acarreta em evolução clínica mais grave e em maiores índices de mortalidade. Contudo, o mecanismo fisiopatológico desta condição clínica ainda se encontra obscuro. Acredita-se que os possíveis precursores sejam as mudanças repentinas na demanda miocárdica, em virtude de fatores como taquicardia, hipotensão, estado de hipóxia, aumento do estado aterotrombótico. Tais condições podem predispor à trombose coronariana e à síndrome coronariana aguda, assim como formação de microtrombos difusos e agressão microvascular, cardiomiopatia associada ao estresse (Cardiomiopatia de Takotsubo), lesão miocárdica relacionada à toxicidade inflamatória da tempestade de citocinas e lesão viral direta aos cardiomiócitos (LANG JP, et al., 2020, ZHOU R, 2020).

Ademais, através do estudo histopatológico de biópsias endomiocárdicas, foi evidenciada a presença de infiltrados inflamatórios de linfócitos-T, com edema intersticial significativo e necrose focal. Outrossim, estudos de Ressonância Magnética (RM) revelaram edema miocárdico e disfunção sistólica ventricular, um padrão radiológico indicativo de cardiomiopatia de Takotsubo reversa. No entanto, são necessários mais estudos para comprovar a relação causal entre miocardite e a infecção por SARS-CoV-2, visto que apenas uma parcela de pacientes portadores de infecções virais desenvolve esse tipo de doença miocárdica (ZHOU R, 2020).

O primeiro caso da cardiomiopatia de Takotsubo, também conhecida como a síndrome do coração partido, foi descrito em 1990 como uma disfunção ventricular esquerda transitória e normalmente reversível que ocorre, principalmente, em mulheres menopausadas após um período de forte estresse emocional ou físico. O seu nome tem origem japonesa e se refere ao termo japonês takotsubo, fazendo alusão ao seu formato ecocardiográfico, onde seu aspecto de balonamento apical assemelhava-se a um objeto usado para a caça de polvos. Inicialmente descrita como uma condição completamente benigna, hoje sabe-se que tal enfermidade pode acarretar em alta mortalidade, com aumento do risco de arritmias ventriculares, tromboembolismo sistêmico e choque cardiogênico (GOMEZ JMD, et al., 2020; KOUTROUMPAKIS E, et al., 2020).

Em uma coorte realizada em Cleveland, foram analisados 1914 pacientes com síndrome coronariana aguda e, dentre eles, $7.75 \%$ dos pacientes foram diagnosticados com cardiomiopatia por estresse durante a pandemia. Entretanto, antes desse período, apenas 1,5 a 1,8\% apresentaram a síndrome de Takotsubo. Por conseguinte, esse estudo evidenciou um aumento considerável do número de casos durante a pandemia (SHAH RM, et al., 2020). 
Além dessas, outra hipótese associada à cardiomiopatia de estresse relacionada a COVID-19 é a lesão imunomediada. Nesta teoria, acredita-se que o fenômeno de "tempestade de citocinas" seja responsável pela disfunção orgânica múltipla. Neste momento, ocorre um acentuado crescimento dos níveis de IL-6, ferritina e D-dímero, assim como, dos biomarcadores cardíacos. Em contrapartida, a infiltração de macrófagos e a elevação de citocinas também ocorrem na síndrome cadiomiopática induzida por estresse de etiologia não infecciosa (TSAO CW, et al., 2020).

Diante disso, pode-se verificar que as vias fisiopatológicas envolvidas na cardiomiopatia de Takotsubo ainda não foram completamente elucidadas, mas guarda profunda relação com a superativação simpática, de tal forma que os níveis de catecolaminas plasmáticas desses pacientes, encontrados no sangue da raiz da aorta e no seio coronariano, são maiores do que aqueles dos indivíduos Classe III na Classificação Cardiológica de Killip. Anteriormente, o estresse emocional era considerado essencial para a cardiomiopatia por estresse, todavia, hoje representa como fator etiológico de 20-39\% dos casos, enquanto o estresse físico, por 35-55\%. Vale salientar, inclusive, que o prognóstico da CT é melhor quando esta é desencadeada por estressores emocionais, comparativamente aos físicos (OKURA H, 2020; FINSTERER J e STÖLLBERGER C, 2020).

Um experimento realizado em rato in vivo com CT, sugeriu que o aumento importante da adrenalina pode induzir cardiodepressão em cardiomiócitos e cardioproteção em um receptor beta-2-adrenérgico ( $\beta$-2-AR-Gi). Altas concentrações de epinefrina, Altas concentrações de epinefrina geram um efeito inotrópico negativo, causando a acinesia das paredes cardíacas envolvidas (OKURA H, 2020).

Esse efeito é resultante da substituição do complexo $\beta$-2-AR com a proteína Gs pela proteína Gi. Desse modo, a estimulação do complexo proteico $\beta$-2-AR-Gi produz a alteração contrátil. A localização e a extensão da disfunção da parede cardíaca na CT podem ser explicadas pela distribuição desses receptores. Recentemente, houve a demonstração in vivo da alteração dos receptores $\beta$-AR. Diante disso, foi mencionado que biópsias de ventrículos esquerdos de pacientes com CT revelaram expressão abundante de proteína $\mathrm{G}$ acoplada a receptor Kinase 2 (GRK2). Isso, por sua vez, também está envolvido no processo de dessensibilização do receptor $\beta$-AR, observado em casos de cardiomiopatia dilatada. Essa dessensibilização promove depressão de contração do ventrículo esquerdo. Ademais, o acoplamento da proteína $\mathrm{G}$ de $\mathrm{Gs}$ a $\mathrm{Gi}$ em $\beta$-AR poderia explicar o envolvimento devido da sua distribuição apical dominante (OKURA H, 2020).

Dentre os gatilhos mais comumente relatados para o desenvolvimento da cardiomiopatia de Takotsubo secundária, encontram-se perda de entes queridos, desastres naturais, perda financeira significativa, violência, doenças respiratórias, intubação, uso de medicações, uso de epinefrina, ansiedade e abstinência de betabloqueadores. Considerando que muitos destes fatores estão presentes em pacientes hospitalizados portadores de COVID-19 e no período pandêmico, esses fatores podem explicar parcialmente o aumento da incidência da condição clínica em questão neste grupo populacional (HEGDE S, et al., 2020; KOUTROUMPAKIS E, et al., 2020).

Os fatores de risco para CT associada à COVID-19 identificados na pesquisa realizada por Hegde $S$, et al. (2020) foram idade avançada, hipertensão, diabetes mellitus, hiperlipidemia, AVC prévio, fibrilação atrial, doença psiquiátrica, hipóxia e pneumonia grave com necessidade de ventilação mecânica.

A ansiedade, o pânico e a depressão se tornaram mais presentes com a pandemia do COVID-19. Acreditase que o estresse relacionado ao período pandêmico, atua, portanto, como gatilho emocional para 0 desenvolvimento da cardiomiopatia induzida por estresse. Corroborando com tais dados, o estudo supracitado realizado em Cleveland, inclusive, não encontrou concordância entre o RT-PCR positivo para COVID-19 e a CT (SHAH RM, et al., 2020; KOUTROUMPAKIS E, et al., 2020).

No estudo de Templin C, et al. (2021) foram avaliados 11 pacientes com COVID-19 associada à cardiomiopatia por estresse, 97 pacientes com apenas COVID-19 e 3215 pacientes somente com CT, a fim de elucidar as vias patogênicas envolvidas na CT secundária à infecção pelo SARS-CoV-2.

Apesar da prevalência do acometimento do sexo masculino pela infecção pelo SARS-CoV-2, a associação COVID-19+CT foi mais prevalente entre as mulheres, correspondentes a $81,8 \%$ dos casos, além de mostrar- 
se mais comum em pacientes com idade avançada (idade média $=72,4$ anos). $72,7 \%$ dos pacientes foram expostos a gatilhos emocionais ou físicos, principalmente a síndrome respiratória aguda pelo coronavírus. A queixa mais comum na cardiomiopatia de Takotsubo foi a dor torácica, enquanto no COVID-19 isolado, foi a dispneia. Pacientes com COVID-19 associada à CT apresentaram fração de ejeção (FE) mais baixa e desfechos piores, comparativamente aos pacientes com CT por outras causas. (TEMPLIN C, et al., 2021).

O diagnóstico de cardiomiopatia de Takotsubo é baseado no quadro clínico, anormalidades eletrocardiográficas, elevação do N-terminal-pro-peptídeo beta natriurético (NT-pro-BNP) e ecocardiograma. Com o avanço da imaginologia, o balonamento apical do ventrículo esquerdo, que representava o único critério diagnóstico necessário, hoje é apenas um deles. A CT pode ser classificada com base no segmento ventricular afetado em variante típica, caracterizada por hipocinesia/ acinesia/ discinesia apical associada à hipercinesia basal, correspondente a $>80 \%$ dos casos, variante invertida ou reversa, marcada por hipocinesia/ acinesia basal com hipercinesia apical, ou ainda cardiomiopatia de Takotsubo global, médio-ventricular e focal. O advento da Ressonância Magnética Cardíaca possibilitou ainda a visualização de acometimento de ventrículo direito, marcador de pior prognóstico à enfermidade em questão (HEGDE S, et al., 2020; SALAH HM e MEHTA JL, 2020; OKURA H, 2020).

Os critérios de Mayo e os da InterTAK são os mais reconhecidos para o diagnóstico da CT, sendo este último capaz de diferenciar a síndrome coronariana aguda da cardiomiopatia de Takotsubo. Por meio do Escore diagnóstico de InterTAK e da pontuação de suas de sete variáveis, dentre elas sexo feminino, gatilho emocional, gatilho físico, ausência de depressão do segmento ST (exceto em aVR), desordens psiquiátricas, desordens neurológicas e alargamento de QT, é possível concluir, se a soma for igual ou superior a 50, o diagnóstico de CT. Do ponto de vista clínico, laboratorial e eletrocardiográfico, a CT se assemelha ao infarto agudo do miocárdio (IAM), mas difere desta última à angiografia de coronárias, que na CT geralmente encontra-se dentro da normalidade. Outro diagnóstico diferencial importante da cardiomiopatia por estresse é a miocardite, mas enquanto a primeira se associa a elevados níveis de troponina, a última se relaciona a níveis de moderados (OKURA H, 2020; FINSTERER J e STÖLLBERGER C, 2020; MOADY G e ATAR S, 2021).

Para o tratamento agudo da Síndrome do Coração Partido, são utilizados IECA, betabloqueadores e diuréticos e, em longo prazo, pode ser lançada mão dos betabloqueadores para reduzir o efeito dos hormônios estressores. Ademais, também existe a possibilidade de tratamentos não medicamentosos, como a psicoterapia. Ressalta-se que o tratamento não varia entre os quadros associados ao COVID (SHAH RM, et al., 2020).

\section{CONSIDERAÇÕES FINAIS}

A cardiomiopatia de Takotsubo tornou-se uma condição clínica de significativa incidência durante a pandemia do COVID-19 e, diante disso, foram suscitadas várias hipóteses para justificá-la. A literatura sugere que a infecção pelo SARS-CoV-2, através de danos diretos, imunomediados e catecolaminérgicos, predispõem a essa cardiomiopatia e elevam a taxa de mortalidade, todavia suas vias fisiopatogênicas exatas ainda não são claras. Ressalta-se ainda que o impacto psicológico causado pela pandemia possa deflagrar tal cardiopatia. Logo, faz-se imperativo a elucidação de seus fatores etiopatogênicos e dos métodos de investigação precoce a fim de aumentar o número de desfechos clínicos favoráveis.

\section{REFERÊNCIAS}

1. BARBIERI L, et al. Takotsubo syndrome in COVID-19 era: Is psychological distress the key?. Journal of Psychosomatic Research, 2021; 140: 110297.

2. EVERAERT BR, et al. Emerging cardiological issues during the COVID-19 pandemic. European journal of clinical investigation, 2020; 50(7): 13270.

3. FINSTERER J, STÖLLBERGER C. SARS-CoV-2 triggered Takotsubo in 38 patients. Journal of Medical Virology, 2020. 
4. GOMEZ JMD, et al. COVID-19-associated takotsubo cardiomyopathy. BMJ Case Reports CP, 2020; $13(12)$ : 23681.

5. HEGDE S, et al. Characteristics and outcome of patients with COVID-19 complicated by Takotsubo cardiomyopathy: case series with literature review. Open heart, 2020; 7(2): 001360.

6. JABRI A, et al. Incidence of stress cardiomyopathy during the coronavirus disease 2019 pandemic. JAMA network open, 2020; 3(7): 2014780-2014780.

7. KIR D, et al. Takotsubo cardiomyopathy caused by emotional stressors in the coronavirus disease 2019 (COVID-19) pandemic era. Journal of cardiac surgery, 2021; 36(2): 764-769.

8. KOUTROUMPAKIS E et al. "Covidsubo": Stress-Induced Cardiomyopathy by Novel Coronavirus Disease 2019. Cardiology, 2020; 145(12): 779-783.

9. LANG JP, et al. A current review of COVID-19 for the cardiovascular specialist. American heart journal, 2020.

10. MADIAS JE. COVID-19, POCUS, and Takotsubo. American Journal of Cardiology, 2021; 141(157).

11. MOADY G, ATAR S. Quarantine-induced Stress Cardiomyopathy (Takotsubo syndrome) during the COVID-19 pandemic. The Israel Medical Association Journal: IMAJ, 2021; 23(3): 149-152.

12. OKURA H. Update of takotsubo syndrome in the era of COVID-19. Journal of Cardiology, 2020.

13. PERETTO G, et al. Acute myocardial injury, MINOCA, or myocarditis? Improving characterization of coronavirusassociated myocardial involvement. European heart journal, 2020.

14. RIVERS J, IHLE JF. COVID-19 social isolation-induced takotsubo cardiomyopathy. The Medical Journal of Australia, 2020; 213(7): 336-336.

15. SALAH HM, MEHTA JL. Takotsubo cardiomyopathy and COVID-19 infection. European Heart Journal-Cardiovascular Imaging, 2020.

16. SHAH RM, et al. Takotsubo Syndrome and COVID-19: Associations and Implications. Current Problems in Cardiology, 2020; 100763.

17. SOLANO-LÓPEZ J, et al. SARS-CoV-2, a novel virus with an unusual cardiac feature: inverted takotsubo syndrome. European heart journal, 2020; 41(32): 3106-3106.

18. SZARPAK L, et al. Correlation between takotsubo cardiomyopathy and SARS-CoV-2 infection. Medical Hypotheses, 2021; 146: 110454.

19. TAZA F, et al. Takotsubo cardiomyopathy triggered by SARS-CoV-2 infection in a critically ill patient. BMJ Case Reports CP, 2020; 13(6): 236561.

20. TEMPLIN C, et al. Takotsubo syndrome in coronavirus disease 2019. American Journal of Cardiology, 2021; 138: 118-120.

21. TSAO CW, et al. COVID-19-associated stress (Takotsubo) cardiomyopathy. Circulation: Cardiovascular Imaging, 2020; 13(7): 011222.

22. ZHOU R. Does SARS-CoV-2 cause viral myocarditis in COVID-19 patients?. European heart journal, 2020; 41(22): 2123-2123. 